the world as an opportunity, unique and challenging, the opportunity to make peace lasting. He believes in a radical solution, but he recognizes that it cannot evolve rapidly; the first steps will inevitably be very modest. Yet in this way alone, he feels, can the faith of science be preserved, the belief in the unqualified value of knowledge and scientific progress.

As a sequel to an interesting and authoritative account of the methods of isotope separation, Urey discusses the motive of such work, strongly maintaining the value of an understanding of natural phenomena for its own sake apart from its usefulness in peace or war. Wheeler gives a stimulating survey of the present knowledge of elementary particles and the prospects for research. In considering the production of high-energy particles, he points out that it would save much scientific man-power if the proposed National Science Foundation would place a contract with a commercial electrical concern for the development of an accelerator. Certainly, in the past a great deal of the best scientific brains have gone to making machines, leaving diminished energy to use them.

The whole pamphlet is full of stimulating ideas and is well worth careful study. G. P. THomson

\section{ECOLOGY AND THE STUDY OF CLIMATE}

$\mathrm{O}$ May 15 last, a joint meeting of the Royal Meteorological.Society and the British Ecological Society was held in the rooms of the Royal Society, Burlington House, at which a series of papers on the relation of ecology to climate was read. The importance of a proper understanding of climatic factors for the elucidation of many ecological problems needs no stressing : nor does the inadequacy of the climatological data usually available at present, particularly when information is needed with regard either to local climates as determined by topographical variations, or micro-climates arising within particular types of vegetation. This meeting was organised as a means of bringing meteorologists and ecologists into closer touch with each other and with problems which have aspects of interest to each and which cannot be solved satisfactorily without their co-operation.

Mr. G. Manley (president of the Royal Meteorological Society) began the discussion with a paper on "Variations in the Length of the Frost-free Period". He stressed the importance of using measurements of temperature obtained under comparable conditions when making comparisons of the length of frost-free periods in different situations. Minimum temperatures taken within a Stevenson screen are, he considers, much more satisfactory for purposes of comparison than grass minimum temperatures, even when these are taken under standard conditions over short grass. This is largely because of the more closely regulated method of exposure within a screen as compared with exposure over short grass in the open. Mr. Manley then gave four interesting examples showing the effect of variations in topography, or soil, on the frequency and severity of night frost, using data obtained from the Monthly Weather Reports of the Meteorological Office. The relatively frosty character of a situation within a narrow and constricted river valley was demonstrated by comparing temperatures taken at Ushew in County Durham, on a hill above the Weir valley, with those taken at Houghall at a point within the valley, $300 \mathrm{ft}$. lower in elevation: Houghall was, on the average, about $5^{\circ}$ colder on frosty nights than Ushew. In the second example, the station at Malvern was compared with that at Perdiswell on the plain below; the lower station again experienced much the moro severe frosts. The importance was stressed of the narrow knife-like ridge of the Malvern Hills as providing a poor collecting ground for cold air on nights when radiation frosts occur, since the severity of night frosts partly depends on the size of such collecting area. In the third exemple, a comparison was made between two different soil types, one the gravelly loam which occurs at the University Farm, Cambridge, and the other the light sandy soil at the station at Lynford, on the Breckland in Suffolk. The topographical formation is very similar at both places and there is no great difference in elevation. Frosts are, however, much more severe and frequent at the Lynford station than at Cambridge. This is largely to be explained by the relatively low heat-capacity and conductivity of the loose sandy soil at Lynford. The fourth example made a comparison of temperatures within and outside a town by comparing the station in Oldham with that at Barton airfield outside the town; in accordance with common experience, the latter proved to suffer very much the more severe frosts. If, using screen minimum temperatures, the frost-free period of the year is determined, its extent will be related to the local climate of the particular situation. Its extent is thus about four and a half months in a relatively low-lying situation in the Midlands, but may be extended for a further four weeks in a more favourable topographical situation. On the other hand, the frost-free period at Lynford on the sandy and frosty Breckland is only just over two months. Finally, Mr. Manley demonstrated the secular trend of minimum temperatures through the last hundred and fifty years. It would appear that in the winter months of January and December frosts are rather less severe than they used to be, but that there has been little or no change in the severity of spring and autumn frost. This agrees with observations made in Scandinavia.

Mr. Manley's paper provided an excellent prelude to the short discussion given by Mr. W. R. Day (Imperial Forestry Institute, Oxford) on "Local Climatic Effects in Tree Growth". In this he referred to the two factors, frost and exposure to wind. Mr. Day stated that the commonly grown larger trees which suffer from frost injury to any serious extent fall roughly into two groups. There are the species, of which European larch and Corsican pine are the most important examples, the growth-cycle of which is markedly out of phase with the annual seasonal cycle. These either begin growth much too early, as with European larch, or continue growth until much too late, as with Corsican pine; and because of this they suffer seriously from frost in many situations. Then there are also the species which naturally would. occur late in the woodland succession and so regenerate under conditions in which previously established vegetation would provide an appreciable amount of shelter from frost, but which are used, for economic purposes in forestry in Great Britain, for making plantations in areas where no such shelter exists. Oak, ash, beech, the spruces and Douglas fir belong to this group. The 'out-of-phase' species suffer the more consistently and severely from frost injury, in suitable situations, and this tends markedly to. restrict the areas within which they can be grown 
successfully. The species of the second group usually suffer severe and widespread frost injury only at intervals. Thus the years 1927,1935 and 1945 were all marked by widespread frost injury, in which such a species as Sitka spruce suffered severely in the more frosty situations. These years of widespread frost injury seem to occur either when severe frost follows after a warm early spring has induced susceptible species to flush early, as in 1945 , or when it occurs late in May when most species of tree have begun to grow.

The topographical situation is of great importance in determining the severity of frost injury; the examples given by $\mathrm{Mr}$. Manley provided excellent instances of this. A further factor of great importance is the form and density of the vegetation which covers the ground. Dense shrubby growth, such as is provided by young plantations, prevents the light winds, which blow on frosty nights, from disturbing the cold air lying within it and also prevent its drainage to lower levels. The severity of frost injury in plantations thus tends to increase after planting until the thicket stage has been reached: later, when a high canopy has been formed, it may decrease appreciably. Lastly, the elevation above sea-level at which any topographical formation occurs influences the severity of frosts. On the whole, the higher the elevation the more severe the injury, other things, including the condition of the susceptible species of tree, being equal. The above observations were based on the occurrence of frost injury in the field, as identified by its morphological characteristics and by the anatomy of affected tissues. It is very rarely that the temperature conditions under which damage occurs are known by actual measurement in situ.

Mr. Day then discussed the effect of exposure to wind on tree-growth. The intensity of exposure is at present estimated qualitatively by foresters and in a highly subjective manner. The data available show that rate of height-growth decreases as intensity of exposure increases, but there are many anomalous observations such as, for example, fast-growing and tall trees recorded as occurring in fully exposed situations. Also, especially in hilly regions, soil fertility often decreases as intensity of exposure increases; but any quantitative estimate of their relative effect on rate of growth is at present impossible, if only because exposure is never estimated quantitatively. The effect of regional topography on the increase in exposure with increasing elevation becomes plain if sample plot data are carefully examined. Thus if the data for European larch in the inland and mountainous counties of Radnor and Brecknock are compared with the data for the coastal and less hilly counties of Carmarthen and Cardigan, it is apparent that whereas in the latter region the proportion of exposed plots increases rapidly with increasing elevation, the increase is comparatively slight in the former. The importance was stressed of obtaining quantitative estimates of climatic factors affecting growth, especially in connexion with the analysis of the relationship between the rate of growth of tree species and their environment.

Prof. D. Brunt (president of the Physical Society) then read a paper on "Some Factors in MicroClimatology". He stressed the importance of stating in the simplest possible terms the manner in which differences in micro-climate arise. The most important facts concerning micro-climates are related to the absorption of solar radiation by day and the loss of heat by outgoing long-wave radiation by night. The reaction of the earth's surface as an irradiated or radiating body depends on its condition. This is usually eomplex, especially when there is a covering of vegetation : it is simplest in the case of bare soil. The factors which influence the temperature of the earth's surface and of the air immediately overlying it were then discussed; for example, the wetness or dryness of the surface; its reflecting power; the conductivity and heat capacity of the material lying immediately below the surface; and the vapour pressure of the overlying air. It is, at present, not possible to say very much about the influence of these factors, except in a very general way. This is partly because of the variety and complexity of conditions which are possible with different types of vegetation, but also because of the great lack of accurate observations relating to specific conditions. Types of temperature gradient which occur above the soil with different types of vegetation were then illustrated by data relating first to a flower-bed (antirrhinums), then to a wheat-field and lastly to high forest. Two very important factors in determining the type of gradient occurring are : first, the position of the insolated, or radiating, surface ; and secondly, the efficiency with which the physical structure of the vegetation prevents the movement of the air within it. The latter point was well illustrated by the conditions prevailing within a mature wheat crop, where the dense mass of stalks largely prevents free movement of air, so that a greenhouse effect develops from the continuous heating throughout the day of a relatively unchanged atmosphere. Because of this, the lowest temperature during the night is not at the soil surface but about midway up the corm stalks. Owing to the inadequacy of the data at present available, the temperature gradients discussed must be regarded as illustrating general types only.

Dr. G. C. Evans then read, on behalf of Dr. P. W. Richards and himself, a paper on the "Climate within a Tropical Rain Forest". The observations brought forward were made in British Guiana. Tropical rain forest consists of several stories, of which the lowest is the most dense. The data were collected at two contrasting points, one within this lowest story and one in the upper canopy of the forest. The most interesting point related to the humidity of the air. This is continuously high at the lower station, being always very close to saturation point; it is, on the other hand, very variable in the upper canopy. This is of considerable ecological interest as reflecting one aspect of the climate within which the smaller trees of such a forest grow; it is also of importance in connexion with those plantation crops, such as cacao, which naturally occur as under-story trees and so need the type of climate which occurs under the protection of a high canopy.

Dr. A. S. Boughey, finally, discussed "The Effect of Chimate on the Distribution of Plant Diseases in the Sudan". Rainfall is the most variable factor, and data were shown to illustrate the types of correlation which have been found to exist between amount of annual precipitation and the incidence of certain important crop diseases. The significance of this correlation is very doubtful with some types of disease, for example, those caused by viruses and rusts ; but with those caused by bacteria, smuts and Fungi Imperfecti it is clear and positive. This close correlation between the incidence of disease and rainfall sometimes enables a forecast to be made of the extent to which control measures would be necessary in particular seasons : this is true of bacterial disease 
of cotton. Sometimes, also, it largely decides which part of the country a crop shall be grown in ; for example, tomatoes remain free from disease if grown in the drier parts of the country.

In the short discussion which followed, it was pointed out that the relationship between animals, and particularly insects, and micro-climates had been entirely neglected, although this forms a most interesting and important part of ecological study. It was thought that in future more attention should be given to this aspect. An interesting reference was made to phenological and climatological work carried out at Bath during the War. This has shown that inversions are a normal occurrence in valleys ; during a year at Bath they occurred on each of $1 \dot{3} 0$ nights. Flowering dates in Bath are later in the valley than on the hill until about the hundredth day in the phenological year (occurring in May), when the higher day temperatures compensate for the relative lowness of night temperatures in the valley. A plea was made for the concentration of future research on specific problems and for the avoidance of the collection of long records unless these are required to answer such problems. The need for greater rigour in the use of the terms 'micro', 'local' and 'regional', in connexion with climate, was also stressed.

The chairman, in closing the meeting, regretted the absence of reference to animal ecology, but the scope of the subject made some restriction inevitable and the 'sessile' plant demanded first attention. $\mathrm{He}$ emphasized the need for the concentration of research on specific problems, and hoped that in the future closer co-operation between meteorologists and ecologists would be possible.

W. R. DAY

The following references are of value in connexion with Mr. Manley's and Prof. Brunt's papers :

Manley, G., "Topographical Features and the Climate of Britain" Geog. J., 103, 241 (1944). "The Effective Rate of Altitudina Change in Temperate Atlantic Climates", Geog. Rev., 35. 408 (1945).

Brunt, D., "Some Factors in Micro-Climatology", Quart. J. Roy. Met. Soc., 71, 1 (1945).

\section{MICROBIOLOGY OF RETTING}

$\mathrm{R}$ ETTING is the process by which the pectic material which binds the fibres to the remainder of the flax stem is broken down and the fibres are liberated. When flax is immersed in water the straw becomes softened and the soluble constituents, which include carbohydrates, glucosides and nitrogen compounds, are extracted. These provide abundant food for growth of the micro-organisms naturally present on the flax plant, and a rapid development of the mixed flora is then accompanied by characteristic chemical changes both in the liquid and in the straw. The retting is effected by certain types of bacteria which break down the pectic complex of the middle lamella of the flax plant, the fibre bundles being first separated from each other and from the cortex and then themselves split lengthwise into fibres.

The quality of the fibre produced and the ease with which it is afterwards spun into yarns and fabrics depend in a large measure on the proper control of this process of retting. Thus the superb quality of Courtrai flax was often attributed to the peculiar properties of the waters of the Lys between
Welveghem and Courtrai. Probably, however, it depended much more, as it still depends, on the quality of the Flemish retters, who possess an understanding of flax and its ways acquired through generations of practice in the art.

The work of van Tieghem ${ }^{1}$, of Fribes ${ }^{2}$, and of Beijerinck and van Delden ${ }^{3}$ early indicated that anaerobic spore-forming bacteria (now regarded as strains of Clostridium butyricum) were probably responsible for the retting action in ordinary stagnant rets. Carbone and co-workers ${ }^{4,5,6,7}$ later claimed that Clostridium felsineum, an organism which they isolated from Italian hemp-retting pits, was particularly active in retting and produced fibre of fine quality. Cultures of this organism were added as part of the procedure in the Carbone industrial process for retting flax. Later workers in other Continental countries have noted this organismrecognized by the bright orange colonies which it forms on suitable media-among the flora of anaerobic rets. In the retting process discovered by Rossi and co-workers $8, \theta, 10,11$ in Italy, patented by Rossi ${ }^{12}$, and established for a time industrially at Bonnétable in France (Carter ${ }^{13}$ ), a current of air was blown through the contents of the retting tank during the course of the ret. It was claimed that under these conditions aerobic bacteria were the active retting agents, and cultures of $B$. comesii, a facultative spore-forming bacillus, were added at the beginning of retting to hasten and improve the process.

In order to control the end point of retting and to avoid weakening of the fibre through over-retting, various procedures have been introduced to retard bacterial growth in the later stages of retting. These are all based upon the principle that withdrawal of leach liquor, or periodic replacement of part of the retting liquor with fresh water, removes a large proportion of the nutrient material upon which active bacterial growth depends. There are, in fact, a large number of retting processes, wide differences of opinion as to the relative merits of each process, and constant attempts to introduce improvements. This condition reflects the fact that, in the past, retting has been regarded mainly as an art, improve. ments in the process have been largely empirical, and scientific investigation has been meagre.

Growth of micro-organisms in the retting liquor during an anaerobic ret results in the formation of organic acids, including butyric acid, and at the end of the ret a large volume of a highly polluting and evilsmelling liquor remains for disposal. This problem in disposal has in the past frequently been solved by ignoring its existence, as, for example, in dam-retting in Ireland or in river-retting in Belgium. The growth of popular movements to preserve amenities, and of legislation to restrain those who would despoil them, have, however, assisted the tendency in most countries to replace these comparatively primitive methods by controlled retting in tanks.

These matters were considered at a joint meeting of the Association of Applied Biologists and the Microbiological Panel of the Society of Chemical Industry, held at the London School of Hygiene and Tropical Medicine on April 12, when two papers were read. The first paper was by Mr. T. W. Brandon and Dr. C. B. Taylor on "Recent Developments in the Retting of Flax and Disposal of the Waste Waters" ; the second, by Dr. L. A. Allen, dealt with "Recent Developments in the Microbiology of Retting". These authors described investigations carried out during the War by the Water Pollution 